\title{
DEVELOPMENT OF BUILDING INFORMATION MODELING TECHNOLOGIES AND THEIR IMPLEMENTATION IN THE FIELD OF MODERN RUSSIAN DESIGN
}

\author{
Julia Skripkina*, Olga Mishchenko, Alexander Velikanov \\ Southwest State University, Kursk, Russian Federation
}

This article discusses a brief history of computer design in general and BIM (Building Information Modeling) in particular. The main benefits of BIM are shown. The benefits of their implementation in Russian architectural and design organizations are justified.

Key words: computer program, design, buildings, structures, modeling, design, architecture

\section{INTRODUCTION}

The development of the construction industry contributed to the expansion of scientific and applied research in the development and implementation of new forms, methods and systems. Computer-aided design (CAD) systems have gone through several stages of development during their existence. CAD is most successfully used in architectural, structural design and construction, where over the past few decades, programs of simple two-dimensional construction of drawings have turned into applications of integrated information modeling [1].

While foreign engineers and architects have been actively developing and using BIM technologies for about two decades, it is only in recent years that building information modeling has been actively developed in Russia.

\section{MATERIALS AND METHODS FOR SOLVING THE PROBLEM}

The object of research of this article is the direct implementation of BIM (Building Information Modeling) around the world, in particular, in Russia. The relevance of this topic can not be argued, as the introduction of BIM-technology everywhere allows you to solve a number of problems: much reduced design time, increases the efficiency of operation of the finished building, reduces the number of alterations, reduces the number of errors, becomes less "gaps" in information.

As such, the interest of engineers in the computer as a means to facilitate their daily tasks appeared around the late fifties, early sixties of the XX-th century. At this point, large production facilities in such companies as: "Renault", "Citroen", "Boeing", as well as universities are conducting research on the study of ways to build two-dimensional geometry. After some time, there are descriptions of ways to build three-dimensional geometry such as boundary representation and constructive solid geometry [2]. These methods are still relevant for $3 \mathrm{D}$ modeling programs. By the early $60 \mathrm{~s}$, there was a sufficient mathematical basis for writing specialized engineering software.
The first such program was Sketchpad, written in 1963 by a developer from the Massachusetts Institute of Technology Ivan Sutherland. Sketchpad has become the prototype of a number of programs written using the technology we now call CAD (Computer-Aided Design) or computer-aided design. The prototype of the program written using the next generation BIM technology (Building Information Modeling) was the software package Building Description System (BDS). BDS was a database of objects where the user could take objects from this database and place them in the model space. BDS was written by Charles Eastman, the architect by education. In addition to writing the program itself, he also wrote a number of articles where he substantiated the efficiency of using a computer compared to standard design tools. And, although BDS was never used in real building design, several of its analogues appeared at once in the next 5 years.

One of these analogues was RUCAPS (Riyadh University Computer Aided Production System), which, like all previous developments, was not sold, as we used to, on some electronic media, and was delivered together with workstations. This meant that only very large design companies could afford it. However, by the mid-eighties, there is the first project for the reconstruction of the building, designed with the help of computer graphics.

The first mass program for computer design was Auto$C A D$, released in 1982. AutoCAD was the absolute leader in the field for the next 25 years.

In 1984, Hungarian developer Gabor Poer wrote ARCHICAD-the architect's main tool until 2000. This year, its main competitor, Revit, appeared. Several innovations were implemented in the 2000 version. In particular, objects have parametric dependencies, and the user has the opportunity to create their own library elements.

The development of complex programs is the most difficult and time-consuming part of the work [3].

BIM (Building Information Modeling) is a comprehensive program that uses a common three-dimensional uniform for the model and tools, as well as a base, replenished 
and improved in the design process. Building information modeling (BIM) is the process of collective creation and use of building information, forming the basis for all decisions throughout the life cycle of the object (from planning to design, release of working documentation, construction, operation and demolition) [3].

The main tasks that guide organizations implementing BIM technologies are:

- $\quad$ increasing the efficiency of software;

- $\quad$ work with a single database of the object;

- obtaining a visual model;

- $\quad$ objective receipt of information about the facility;

- $\quad$ increasing the level of coordination of participants in the design and construction process;

- $\quad$ improving the quality of project documentation;

- improving the quality of construction;

- $\quad$ increasing competitiveness in the global market.

Another important task to be solved when implementing information modeling of buildings in the design and construction is to reduce the cost of construction in order to save public and private funds. This is due to the fact that BIM-modeling allows you to calculate the cost, terms of work, the accuracy of determining the amount of necessary materials and construction equipment, performing risk calculations and so on at an early stage [4].

The idea of a systematic approach - the consideration of a phenomenon as a complex whole, consisting of a set of interconnected elements - is not new for many branches of knowledge [6].

\section{RESULTS AND DISCUSSION}

According to the results of research conducted in Russia and abroad, the introduction of BIM can significantly improve the performance of the design and construction industry, increase competitiveness at the global level, control the design object at all stages of its life cycle [5]. BIM-modeling helps to achieve the goals set In the strategy of innovative development of the construction industry of the Russian Federation until 2030, which, in turn, will increase the efficiency of the industry and improve the quality of construction products [6].

We are able to see the fruits of BIM technologies even now. Consider the Sydney Opera house as an example. This building was destined to become almost the first of the masterpieces of world architecture, which many years after the construction of an information model, designed for the design, reconstruction and management of the daily operation of the object (Fig.1).

World-famous for its sensational roofs, the Sydney Opera house has been designed since 1957 by Danish architect JornUtzon and engineers from the British firm Ove Arup (Fig. 2). Difficulties in the design of the building were offset by the use of BIM-technologies, which helped to create a successful aerodynamic shape of the entire structure and allowed it to successfully withstand almost constant wind loads caused by its unusual location.

In the Russian sphere, BIM-designing is just beginning to enter into widespread use, however, there are examples of ambitious projects, for example, the Mordovia Arena stadium, designed for 45,000 spectators (Fig. 3). As con-

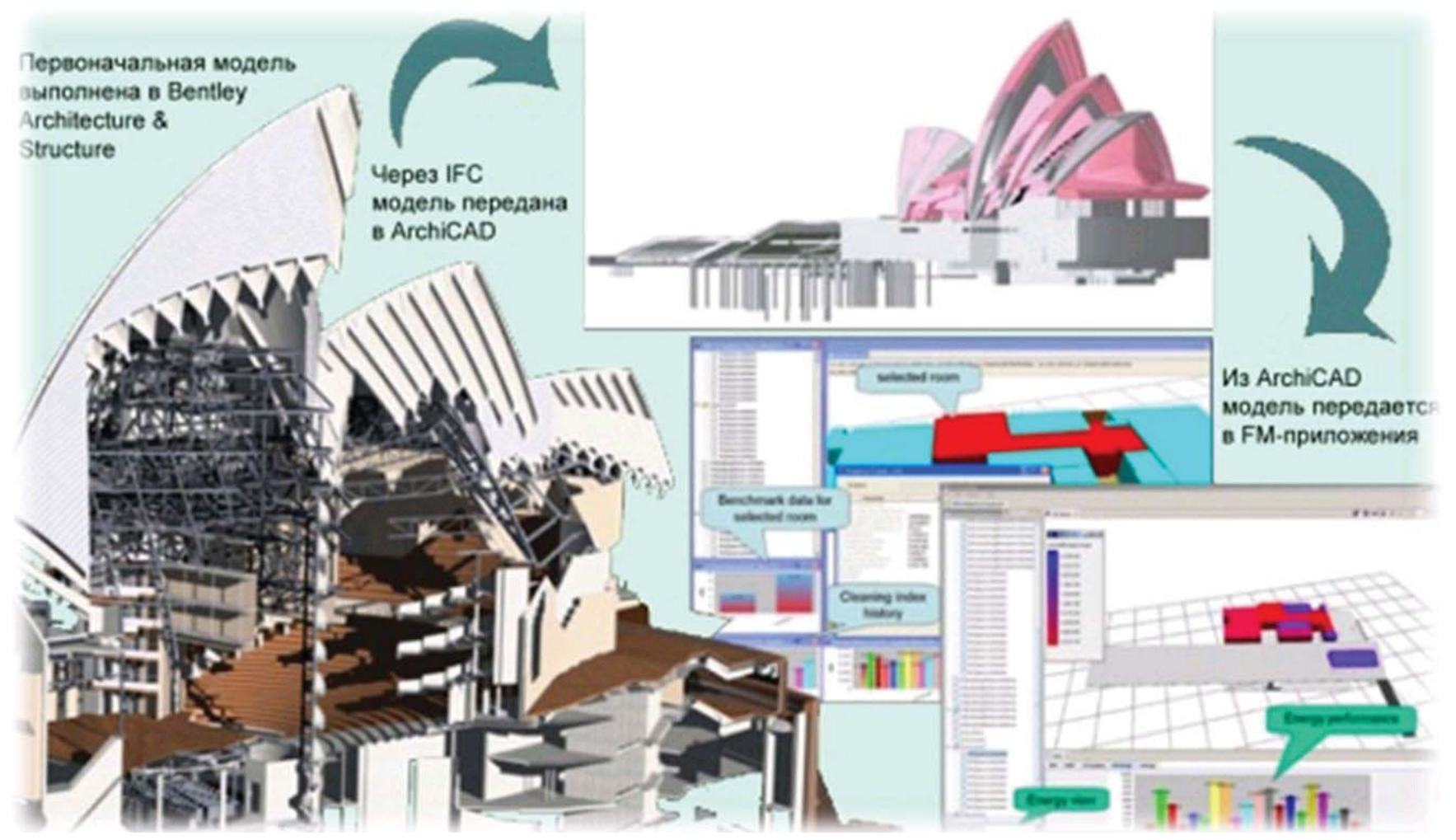

Figure 1: Diagram of data transfer of the building information model between the various programs involved in its creation using the IFC format 


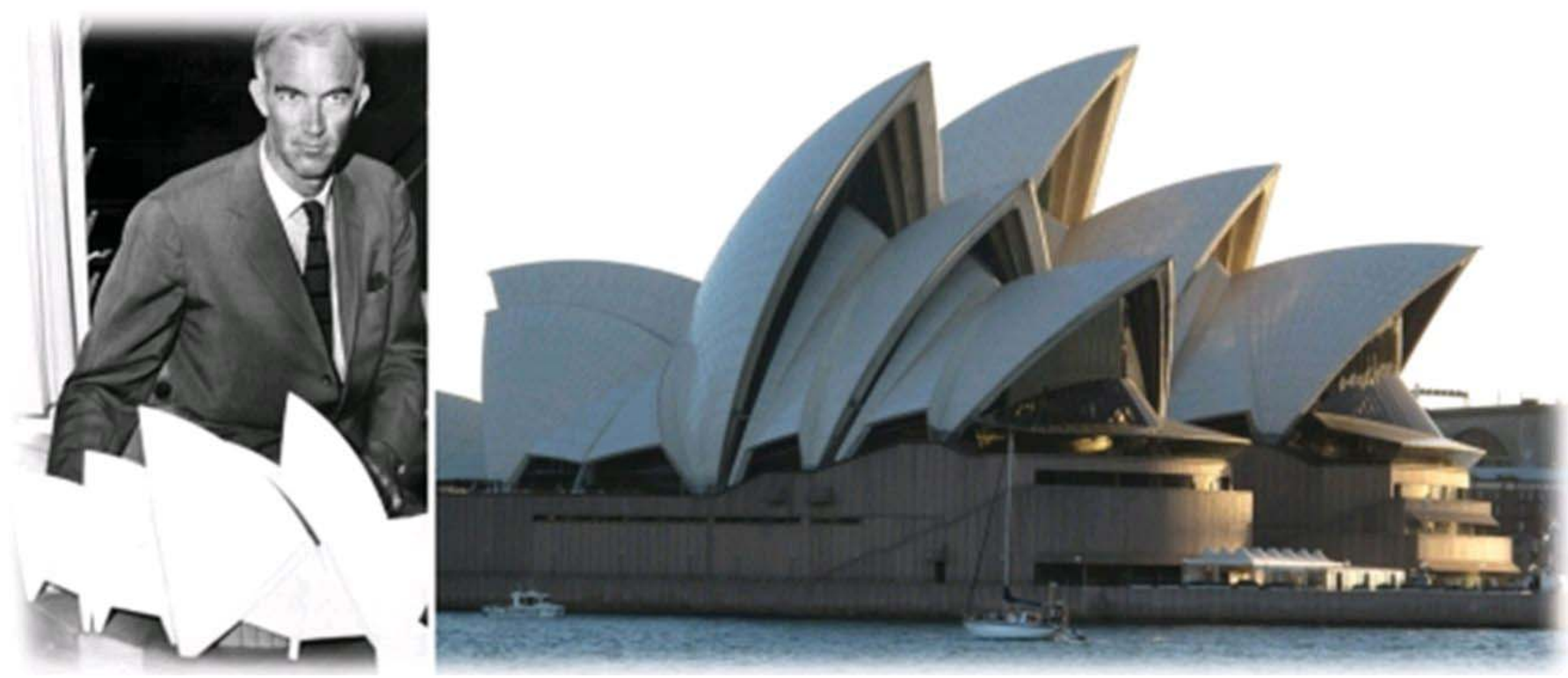

Figure 2: The Sydney Opera House and its author, Danish architect JornUtzon. In 1957, BIM technology was not yet available, so the model of such a complex structure was represented by a cardboard layout

ceived by the architects, the bowl of the arena resembles a bright red sun - one of the symbols of the Republic of Mordovia. The location of the bowl above the two-story stylobate creates the effect of lightness. In addition, the shell of the stadium is of a non-standard oval shape: it gradually decreases to the north and south stands and then again rises to the east. The base of the stadium is $88 \mathrm{~L}$-shaped consoles with a height of 40 meters and a projection of 49 meters. All of them are designed from steel pipes, which leads to a small total weight of the coating structures - about 6000 tons.

During the initial development of the design documentation, the project was finalized over the course of six months by the general contractor for the construction of

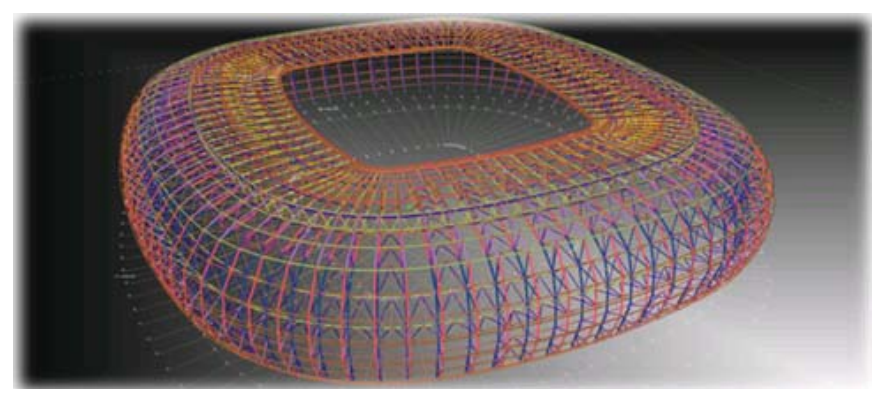

Figure 3: Information model of the Mordovia Arena stadium

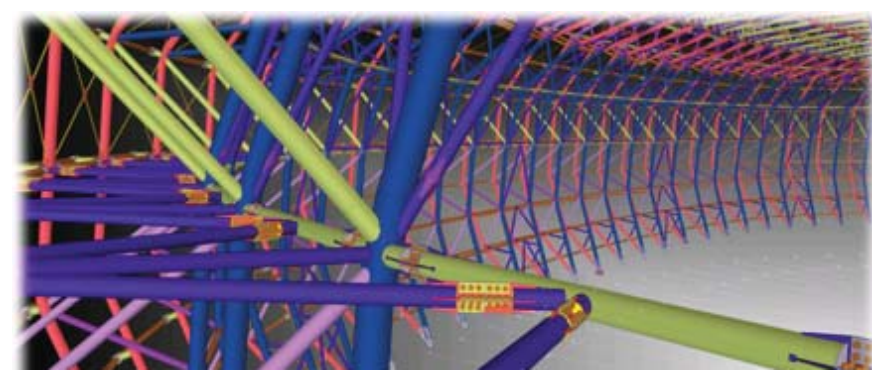

Figure 4: A fragment of the Mordovia Arena model the stadium of Kazan Production and Construction Association LLC, together with Belenergomash specialists. According to CAD support specialist Dmitry Dolzhenkov, "the plant was to produce complex structures of metal geometry for the stadium with an accuracy of $10 \mathrm{~mm}$ with a span of up to $60 \mathrm{~m}$ and a large number of welded joints. The particular difficulty of the project was that it did not allow delays. "

It is noteworthy that Belenergomash independently developed the technical conditions of production and coordinated them with the design institutes involved in the construction of the facility. After that, in order to be able to start work on the project, the plant's specialists worked out the technology of assembly and welding of elements on samples for several months (Fig. 4).

\section{CONCLUSIONS}

It was BIM that helped to organize a transparent workflow and ensure productive interaction of all involved professionals. After all, initially, BIM technology was developed for use at the design stage; now BIM is a tool that can radically change the entire construction industry as a whole. The introduction of BIM technology in Russia is of enormous relevance, as it leads to a multiple reduction in design time, increase the efficiency of operation of the finished building, reduce the number of rework, reduce the number of errors, there are fewer "gaps" in information.

\section{REFERENCES}

1. Zelenina V.G.,Morar E.S. 2015. The concept of information modeling of buildings. Bulletin of PNIPU. Applied Ecology. Urban Studies No. 1: 118-125.

2. Foley, James D.1996. Computer Graphics: Principles and Practice. Addison-Wesley Professional, Pp. 557-558. 
3. Pozdnyakov, L. A. [2018]. The principles of environmental program formation for district planning. Journal of Applied Engineering Science, 16(1), 75-78.

4. Litvinenko E.V, Ustyuzhanina I.A. 2015. The use of building information modeling (BIM-technologies) in Russia. Economics and business: theory and practice. No.10. https://cyberleninka.ru/article/n/primenenie-informatsionnogo-modelirovaniya-zdaniy-bim-tehnologiy-v-rossii.

5. Korol M.G. 2014. BIM: information modeling - the digital age of the construction industry.Stroymetall. No. 9: 26-30.
6. Pozdnyakov, L. A. [2017]. Main methodological principles of solving environmental problems in urban planning. Journal of Applied Engineering Science, 15(3), 300-306.

7. The official website of the company AUTODESK: http://www.autodesk.ru.

8. The official website of the Ministry of Construction of the Russian Federation: http://www.minstroyrf.ru. 